\title{
Effect of machined interfacet allograft spacers on cervical foraminal height and area
}

\author{
Laboratory investigation
}

\author{
Lee A. Tan, M.D., ${ }^{1}$ Carter S. Gerard, M.D., ${ }^{1}$ Paul A. Anderson, M.D., ${ }^{2}$ \\ and Vincent C. Traynelis, M.D. ${ }^{1}$ \\ ${ }^{1}$ Department of Neurosurgery, Rush University Medical Center, Chicago, Illinois; and ${ }^{2}$ Department of \\ Orthopedics \& Rehabilitation, University of Wisconsin, Madison, Wisconsin
}

\begin{abstract}
Object. Iatrogenic foraminal stenosis is a well-known complication in cervical spine surgery. Machined interfacet allograft spacers can provide a large surface area, which ensures solid support, and could potentially increase foraminal space. The authors tested the hypothesis that machined interfacet allograft spacers increase cervical foraminal height and area.

Methods. The C4-5, C5-6, and C6-7 facets of 4 fresh adult cadavers were exposed, and the cartilage was removed from each facet using customized rasps. Machined allograft spacers were tamped into the joints. The spines were scanned with the $\mathrm{O}$-arm surgical imaging system before and after placement of the spacers. Two individuals independently measured foraminal height and area on obliquely angled sagittal images.

Results. Foraminal height and area were significantly greater following placement of the machined interfacet spacers at all levels. The Pearson correlation between the 2 radiographic reviewers was very strong $(r=0.971, p=$ $0.0001)$, as was the intraclass correlation coefficient $(\mathrm{ICC}=0.907, \mathrm{p}=0.0001)$. The average increase in foraminal height was $1.38 \mathrm{~mm}$. The average increase in foraminal area was $18.4 \%\left(0.097 \mathrm{~mm}^{2}\right)$.

Conclusions. Modest distraction of the facets using machined interfacet allograft spacers can increase foraminal height and area and therefore indirectly decompress the exiting nerve roots. This technique can be useful in treating primary foraminal stenosis and also for preventing iatrogenic foraminal stenosis that may occur when the initially nonlordotic spine is placed into lordosis either with repositioning after central canal decompression or with correction using instrumentation. These grafts may be a useful adjunct to the surgical treatment of cervical spine disease. (http://thejns.org/doi/abs/10.3171/2013.11.SPINE131)
\end{abstract}

\section{KEY WORDS • iatrogenic foraminal stenosis - cervical facet • interfacet spacer - facet distraction - cervical fusion $\quad$ cervical foraminal area}

$\mathrm{L}$ oss of intervertebral disc height, cervical extension, facet hypertrophy, and retrolisthesis of cervical vertebrae can significantly decrease cervical foraminal area and potentially cause compression of the exiting cervical nerve root. ${ }^{6,17,18,20,27,33}$ Patients with loss of cervical lordosis who are repositioned in lordosis after a dorsal decompression are at risk for symptomatic iatrogenic foraminal stenosis, with an estimated incidence ranging from $2.6 \%$ to $50 \%$. $1,12,13,21,29$

An interfacet allograft spacer may be a potentially useful adjunct in the surgical treatment of cervical spine disease, especially in reducing the risk of iatrogenic foraminal stenosis. This study is designed to test the hypothesis that interfacet allograft spacers can increase foraminal height and area in the cervical spine.

\section{Methods}

Four fresh adult cadavers were obtained for the study after screening with radiographs and CT scans to ensure the absence of any significant spinal pathology other than age-appropriate degenerative changes. The cervical spine of each cadaver was imaged using the $\mathrm{O}$-arm surgical imaging system (Medtronic) to establish the baseline foraminal dimensions. The C4-5, C5-6, and C6-7 posterior lateral masses of these cadavers were exposed by the senior author. The cartilage from each facet joint was removed using customized elevators and rasps (Facetlift,

This article contains some figures that are displayed in color online but in black-and-white in the print edition. 
Medtronic) (Fig. 1). The machined interfacet allograft spacers (Facetlift, Medtronic) were then tamped into each facet joint (Fig. 2). The spacers were $8 \times 8 \mathrm{~mm}$ and varied in height from 2 to $4 \mathrm{~mm}$. The height was determined by the anatomy of each joint. The cervical spine specimens were scanned again with the $\mathrm{O}$-arm imaging system after placement of the interfacet allograft spacers.

The images obtained before and after interfacet spacer placement were analyzed by 2 reviewers independently using Onis viewer (Digitalcore). The foraminal height, width, and area before and after interfacet allograft spacer insertion were measured for each level on sagittal images using the Onis cursor (Fig. 3). The software automatically calculated the linear and area values. Averaged measurements from these reviewers were compared using the paired ttest.

\section{Results}

The Pearson correlation between the 2 radiographic reviewers was very strong, with $r=0.971(p=0.0001)$, and the intraclass correlation coefficient (ICC) was 0.907 $(\mathrm{p}=0.0001)$. The average foraminal height, width, and area were significantly increased at all levels following insertion of the machined interfacet allograft spacers, as can be seen in Tables 1-3, which present the data acquired from 8 foramina at each level (C4-5, C5-6, C6-7). The overall average foraminal height increase was $1.38 \mathrm{~mm}$. The average height increases were 1.23, 0.85, and 2.05 $\mathrm{mm}$ at $\mathrm{C} 4-5, \mathrm{C} 5-6$, and C6-7, respectively. The overall average increase in foraminal area was $18.39 \%(0.097$ $\left.\mathrm{mm}^{2}\right)$. The average area increases were $18.48 \%, 10.56 \%$, and $26.12 \%$ at C4-5, C5-6, and C6-7, respectively.

\section{Discussion}

Iatrogenic foraminal stenosis is a well-documented complication in cervical spine surgery, especially in posterior cervical spine fusion with instrumentation.,12,13,21

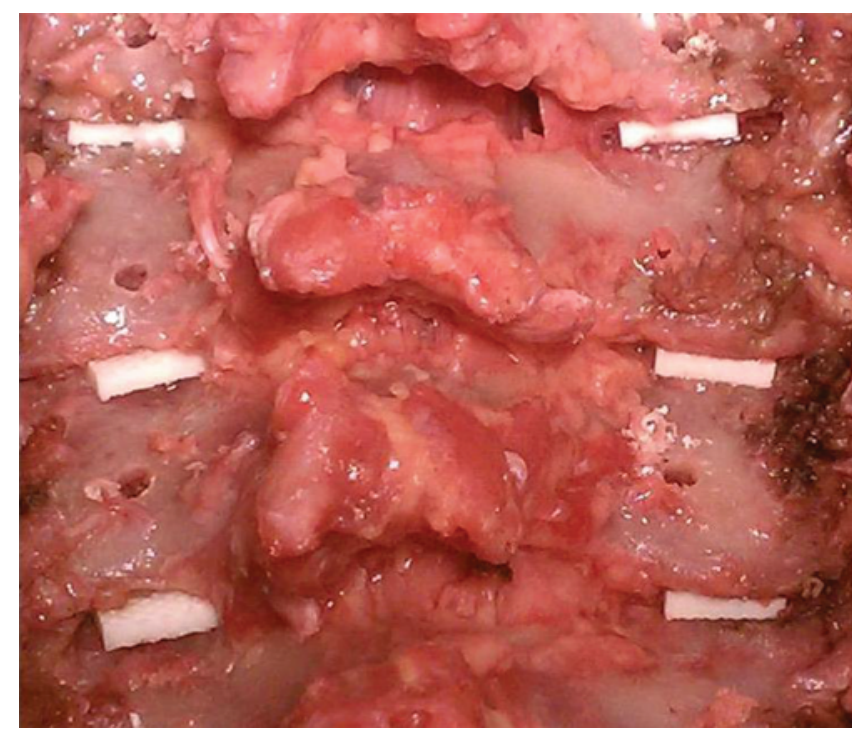

FIG. 2. Photograph demonstrating machined interfacet allograft spacers inserted in the facet joints at $\mathbf{C} 4-5, \mathrm{C} 5-6$, and $\mathrm{C} 6-7$ in a cadaveric specimen.

This complication may occur when a patient presenting with loss of cervical lordosis is repositioned into lordosis after central canal decompression or undergoes correction of alignment using instrumentation during surgical treatment of cervical spine disease. Lu et al. examined the relationship between intervertebral disc height and foraminal area in a cadaveric study. ${ }^{18}$ They found that 1-, 2-, and 3-mm narrowing of the intervertebral disc space corresponded to foraminal area reductions of $20 \%-30 \%$, $30 \%-40 \%$, and $35 \%-45 \%$, respectively. Yoo et al. found that cervical extension of $20^{\circ}$ was associated with $10 \%$ reduction in foraminal diameter and cervical extension of $30^{\circ}$ was associated with $13 \%$ reduction in diameter. ${ }^{33}$ This is equivalent to reductions in foraminal area of $19 \%$ and $24.3 \%$, respectively. In vivo studies by Muhle et al. ${ }^{20}$ and Kitagawa et al. ${ }^{17}$ have also confirmed that cervical ex-

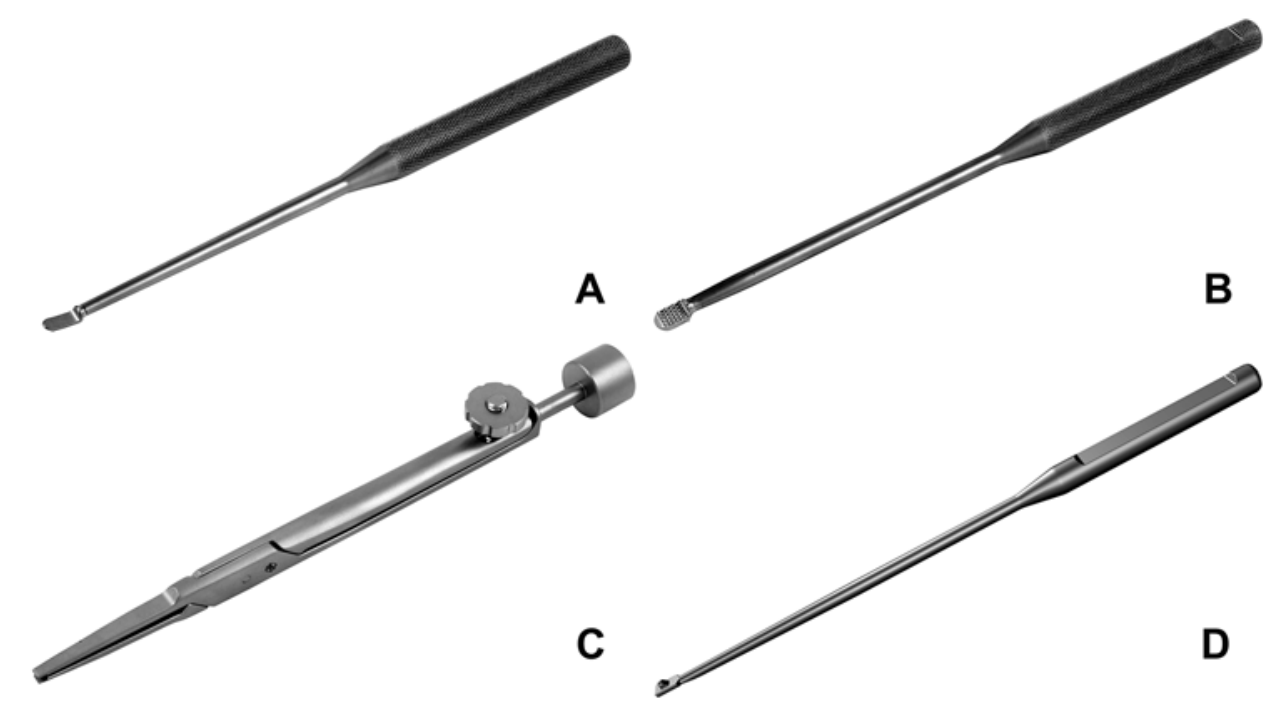

FIG. 1. Photographs of facet elevator (A), $3 \times 8 \times 8-\mathrm{mm}$ facet rasp (B), initial graft holder (C), and final tamp (D). The instruments have a stop to avoid overinsertion into the joint. 


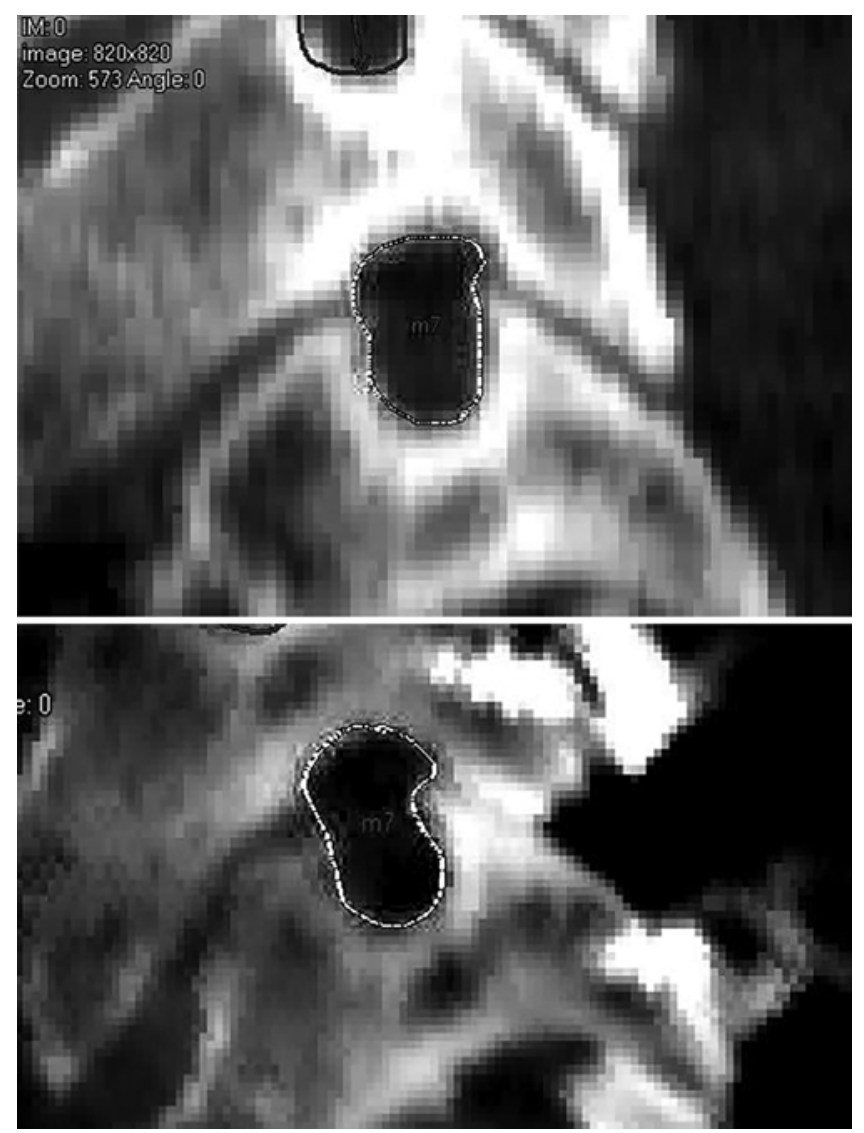

FIG. 3. Left C4-5 foraminal area before (upper) and after (lower) interfacet allograft spacer placement.

tension can significantly reduce the foraminal area. These publications are consistent with our results showing that 1-2 $\mathrm{mm}$ of facet distraction significantly increases facet height and area.

Estimates of the risk of developing symptomatic iatrogenic foraminal stenosis from posterior cervical spine fusion range from $2.6 \%$ to $50 \% .^{1,12,13,21,29}$ The C-5 nerve root is especially prone to injury, and the risk of C-5 palsy has been reported to be 11.6 times greater in patients treated with instrumentation as compared with those without. ${ }^{28}$ The exact cause of C-5 palsy is unknown, but it is likely multifactorial, with one of the major risk factors being the presence of foraminal stenosis. ${ }^{21}$ Katsumi et al. advocate prophylactic foraminotomy to decrease the incidence of C-5 palsy. ${ }^{16}$ However, foraminotomy reduces

TABLE 1: Mean foraminal height before and after interfacet allograft placement

\begin{tabular}{cccc}
\hline & \multicolumn{2}{c}{ Height in $\mathrm{mm}^{*}$} & \\
\cline { 2 - 3 } Level & Baseline & After Graft & Increase $(\mathrm{mm})$ \\
\hline C4-5 & $10.13 \pm 1.84$ & $11.36 \pm 1.32$ & 1.23 \\
C5-6 & $10.18 \pm 1.42$ & $11.03 \pm 1.24$ & 0.85 \\
C6-7 & $10.06 \pm 1.32$ & $12.11 \pm 1.48$ & 2.05 \\
overall & $10.12 \pm 1.51$ & $11.50 \pm 1.40$ & 1.38 \\
\hline
\end{tabular}

* Mean \pm SD.
TABLE 2: Mean foraminal width before and after interfacet allograft placement

\begin{tabular}{lccc}
\hline & \multicolumn{2}{c}{ Width in $\mathrm{mm}^{*}$} & \\
\cline { 2 - 3 } Level & Baseline & After Graft & Change $(\mathrm{mm})$ \\
\hline C4-5 & $5.71 \pm 2.33$ & $6.66 \pm 2.50$ & 0.95 \\
C5-6 & $6.09 \pm 2.19$ & $5.85 \pm 2.06$ & -0.25 \\
C6-7 & $5.95 \pm 2.32$ & $6.51 \pm 2.43$ & 0.56 \\
overall & $5.92 \pm 2.24$ & $6.34 \pm 2.32$ & 0.42 \\
\hline
\end{tabular}

${ }^{*}$ Mean \pm SD.

the amount of bone available for screw purchase and may adversely impact overall stability. The machined interfacet allograft spacer is a facet distraction device with a large surface area that provides solid support for the spinal column and distracts the facet joint, thereby stiffening the spinal segment, which should facilitate arthrodesis., ${ }^{5,23}$ It also increases foraminal height and area, which can indirectly decompress the exiting nerve roots. Goel and Shah have described their experience with titanium interfacet spacers in the treatment of cervical spondylotic myelopathy and radiculopathy, ${ }^{10}$ reporting an average of $2.2 \mathrm{~mm}$ increase in foraminal height in a group of 36 patients. This finding is consistent with the data from our cadaveric study. Additionally, Goel et al. reported that interfacet distraction produced a significant increase in the facet height, disc height, and interspinous height, as well as reducing buckling of the posterior longitudinal ligament and ligamentum flavum. All of the patients in their series had clinical improvement in myelopathy and radiculopathy. Bony fusion also occurred in all patients. These results suggest that the use of interfacet spacers not only can increase the foraminal area via facet distraction but also can affect overall cervical spine biomechanics by facet arthrodesis and may have favorable effects in the degenerative process. In the setting of mild or moderate foraminal stenosis it is possible that the placement of facet spacers alone may be adequate to relieve clinical symptoms, and they may prevent radiculopathy in patients with asymptomatic severe stenosis.

It is commonly believed that degeneration in the spine begins with loss of water content in the intervertebral disc as part of the aging process, which may lead to loss in disc height, osteophyte formation, spondylolisthesis, facet arthropathy, and ligamentous hypertrophy. These spondylotic changes may lead to compression of

TABLE 3: Mean foraminal area before and after interfacet allograft placement

\begin{tabular}{lccc}
\hline & \multicolumn{2}{c}{ Area in $\mathrm{mm}^{2 *}$} & \\
\cline { 2 - 3 } Level & Baseline & After Graft & Increase (\%) \\
\hline C4-5 & $0.53 \pm 0.17$ & $0.63 \pm 0.16$ & 18.48 \\
C5-6 & $0.48 \pm 0.10$ & $0.53 \pm 0.13$ & 10.56 \\
C6-7 & $0.55 \pm 0.16$ & $0.69 \pm 0.18$ & 26.12 \\
overall & $0.52 \pm 0.14$ & $0.62 \pm 0.17$ & 18.39 \\
\hline
\end{tabular}

* Mean \pm SD. 
neural elements and clinical signs of radiculopathy and myelopathy. Goel et al. have challenged this widely held perspective and have proposed an alternative theory, in which spinal spondylosis may actually begin with facet instability and the disc degeneration and other spondylotic changes occur secondarily. ${ }^{8-10}$ The support for this alternative hypothesis lies in the reversal of cervical spondylotic changes seen after facet distraction using titanium interfacet spacers in their patients. ${ }^{10}$

The facet joint has been shown to be responsible for up to $25 \%$ of axial load sharing in the lumbar spine. ${ }^{32}$ Finite element models of the ligamentous cervical spinal segments have estimated that cervical facet joints can be responsible for up to $23 \%$ of axial loading. . $^{11,22}$ In addition, the facet joint provides resistance to shearing, distraction, and lateral bending forces, which is important in maintaining the normal biomechanics of the spine. ${ }^{4,25,26,34}$ Similar to other synovial joints, the facet joint can undergo progressive degeneration as a result of aging, inflammation, infection, and mechanical trauma. ${ }^{15,19,30}$ Since the intervertebral disc and facet joint both participate in load sharing in the spine, loss of disc height or spondylolisthesis could change the normal spine biomechanics and theoretically increase the mechanical stress on the facet joint and lead to accelerated facet degeneration. ${ }^{15}$ The cartilage in the articulating surface is one of the first components affected in the degeneration process, which can be manifested by cartilaginous loss, sclerosis, exposure of underlying bony pillars, osteophyte formation, synovial cyst formation, and capsule calcification. The degenerative changes eventually occur in the bony articular surfaces of the facet joint. The increase in mechanical stress can stimulate osteoblasts to synthesize bone, forming osteophytes or bone spurs and leading to facet hyper-

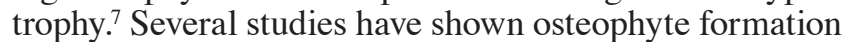
along the facet capsule attachment where to stress from the hyper-mobile joint is the greatest. ${ }^{2,3}$ The bone on bone contact in a degenerative facet can also lead to pain from both afferent nerves in the facet joint and the inflammatory cytokine leakage from the joint capsule to surrounding tissue. ${ }^{14}$ In addition, synovial cyst or facet hypertrophy may also cause direct neural element compression. Facet degeneration can be graded based on CT imaging as described by Pathria et al., where Grade I corresponds to facet joint space narrowing, Grade II corresponds to facet sclerosis or hypertrophy, and Grade III corresponds to osteophyte formation. ${ }^{24}$

Many patients with cervical myelopathy and radiculopathy have loss of normal cervical lordosis. Surgical management in these cases may require decompression and fusion. Restoration or maintenance of lordosis after decompression is desirable because it facilitates posterior shift of the spinal cord and contributes to normal sagittal balance. As discussed previously, an increase in lordosis can produce a decrease in foraminal area and may result in radiculopathy due to foraminal stenosis. When the anterior approach is used, the interbody graft can add at least $5^{\circ}$ of lordosis at each level. Although the increase in intervertebral distance created by the anterior interbody graft may help to increase foraminal height, the relative cervical extension may negate this effect. Significant mul- tilevel cervical spinal deformities secondary to disease processes such as rheumatoid arthritis may require anterior, posterior, or combined approaches. ${ }^{31}$ In these cases, the use of interfacet spacers may be useful to increase foraminal area, facilitate decompression of the cervical nerve root, and decrease the risk of iatrogenic foraminal stenosis. Interfacet allograft can be used in combination with laminectomy or laminoplasty for management of spinal cord compression. The interfacet allograft spacers also have a large surface area and thus can provide solid support and stability. The axial load placed on the facets also facilitates arthrodesis and bony fusion, and thus may potentially improve overall surgical outcome.

The major limitation of this study is the small sample size. However the high degree of accuracy of our measurement technique mitigates this shortcoming. Further research into foraminal changes after instrumentation and attempted segmental correction would be of interest. Although the surface area available for grafting is larger than normal we do not know from this biomechanical study whether fusion will occur. Nevertheless, our clinical experience has been excellent with a high rate of fusion success when interfacet grafts are used with instrumentation.

\section{Conclusions}

Our data confirm the hypothesis that machined interfacet allograft spacers increase cervical foraminal height and area. The modest distraction of the facets produced by the machined interfacet allograft spacers increase the foraminal area and therefore can indirectly decompress the exiting nerve root. These grafts should prevent the foraminal stenosis that may occur when the initially nonlordotic spine is placed into lordosis with either repositioning after decompression or with correction using instrumentation. This is particularly important at $\mathrm{C} 4-5$ due to the exquisite sensitivity of the C-5 root. Machined interfacet allografts provide solid support and should be associated with a high rate of arthrodesis since the facets bear axial load that places the grafts under compression. These grafts may be a useful adjunct to the surgical treatment of cervical spine disease and may help to reduce incidence of iatrogenic foraminal stenosis.

\section{Disclosure}

This study was funded by Medtronic. In addition, Dr. Traynelis reports having a consultant and patent holder relationship with Medtronic and receiving institutional fellowship support from Globus Medical. Dr. Anderson reports having an ownership interest in Pioneer Surgical, SI Bone, Spartec, Expanding Orthopedics, and Titan Surgical; having a consultant relationship with Pioneer Surgical, Aesculap, and Medtronic; and receiving royalties from Stryker and Pioneer Surgical.

Author contributions to the study and manuscript preparation include the following. Conception and design: Traynelis. Acquisition of data: Traynelis, Tan, Gerard. Analysis and interpretation of data: Traynelis, Tan, Gerard. Drafting the article: Tan. Critically revising the article: all authors. Reviewed submitted version of manuscript: all authors. Approved the final version of the manuscript on behalf of all authors: Traynelis. Statistical analysis: Traynelis. Study supervision: Traynelis. 


\section{References}

1. Abumi K, Shono Y, Ito M, Taneichi H, Kotani Y, Kaneda K: Complications of pedicle screw fixation in reconstructive surgery of the cervical spine. Spine (Phila Pa 1976) 25:962-969, 2000

2. Adams MA, Hutton WC: The mechanical function of the lumbar apophyseal joints. Spine (Phila Pa 1976) 8:327-330, 1983

3. Boszczyk BM, Boszczyk AA, Putz R, Büttner A, Benjamin M, Milz S: An immunohistochemical study of the dorsal capsule of the lumbar and thoracic facet joints. Spine (Phila Pa 1976) 26:E338-E343, 2001

4. Cusick JF, Yoganandan N, Pintar F, Myklebust J, Hussain H: Biomechanics of cervical spine facetectomy and fixation techniques. Spine (Phila Pa 1976) 13:808-812, 1988

5. Daniel RT, Muzumdar A, Ingalhalikar A, Moldavsky M, Khalil S: Biomechanical stability of a posterior-alone fixation technique after craniovertebral junction realignment. World Neurosurg 77:357-361, 2012

6. Ebraheim NA, Liu J, Shafiq Q, Lu J, Pataparla S, Yeasting RA, et al: Quantitative analysis of changes in cervical intervertebral foramen size with vertebral translation. Spine (Phila Pa 1976) 31:E62-E65, 2006

7. Fujiwara A, Lim TH, An HS, Tanaka N, Jeon CH, Andersson GB, et al: The effect of disc degeneration and facet joint osteoarthritis on the segmental flexibility of the lumbar spine. Spine (Phila Pa 1976) 25:3036-3044, 2000

8. Goel A: Facet distraction-arthrodesis technique: can it revolutionize spinal stabilization methods? J Craniovertebr Junction Spine 2:1-2, 2011

9. Goel A: Facet distraction spacers for treatment of degenerative disease of the spine: rationale and an alternative hypothesis of spinal degeneration. J Craniovertebr Junction Spine 1:65-66, 2010

10. Goel A, Shah A: Facetal distraction as treatment for singleand multilevel cervical spondylotic radiculopathy and myelopathy: a preliminary report. Technical note. J Neurosurg Spine 14:689-696, 2011

11. Goel VK, Clausen JD: Prediction of load sharing among spinal components of a C5-C6 motion segment using the finite element approach. Spine (Phila Pa 1976) 23:684-691, 1998

12. Heller JG, Silcox DH III, Sutterlin CE III: Complications of posterior cervical plating. Spine (Phila Pa 1976) 20:24422448, 1995

13. Hojo Y, Ito M, Abumi K, Kotani Y, Sudo H, Takahata M, et al: A late neurological complication following posterior correction surgery of severe cervical kyphosis. Eur Spine J 20: 890-898, 2011

14. Igarashi A, Kikuchi S, Konno S, Olmarker K: Inflammatory cytokines released from the facet joint tissue in degenerative lumbar spinal disorders. Spine (Phila Pa 1976) 29:2091-2095, 2004

15. Jaumard NV, Welch WC, Winkelstein BA: Spinal facet joint biomechanics and mechanotransduction in normal, injury and degenerative conditions. J Biomech Eng 133:071010, 2011

16. Katsumi K, Yamazaki A, Watanabe K, Ohashi M, Shoji H: Can prophylactic bilateral $\mathrm{C} 4 / \mathrm{C} 5$ foraminotomy prevent postoperative C5 palsy after open-door laminoplasty?: a prospective study. Spine (Phila Pa 1976) 37:748-754, 2012

17. Kitagawa T, Fujiwara A, Kobayashi N, Saiki K, Tamai K, Saotome K: Morphologic changes in the cervical neural foramen due to flexion and extension: in vivo imaging study. Spine (Phila Pa 1976) 29:2821-2825, 2004

18. Lu J, Ebraheim NA, Huntoon M, Haman SP: Cervical intervertebral disc space narrowing and size of intervertebral foramina. Clin Orthop Relat Res (370):259-264, 2000

19. Michel-Batôt C, Dintinger H, Blum A, Olivier P, Laborde F,
Bettembourg-Brault I, et al: A particular form of septic arthritis: septic arthritis of facet joint. Joint Bone Spine 75:78-83, 2008

20. Muhle C, Resnick D, Ahn JM, Südmeyer M, Heller M: In vivo changes in the neuroforaminal size at flexion-extension and axial rotation of the cervical spine in healthy persons examined using kinematic magnetic resonance imaging. Spine (Phila Pa 1976) 26:E287-E293, 2001

21. Nakashima H, Imagama S, Yukawa Y, Kanemura T, Kamiya M, Yanase M, et al: Multivariate analysis of C-5 palsy incidence after cervical posterior fusion with instrumentation. Clinical article. J Neurosurg Spine 17:103-110, 2012

22. Pal GP, Routal RV: A study of weight transmission through the cervical and upper thoracic regions of the vertebral column in man. J Anat 148:245-261, 1986

23. Park J, Scheer JK, Lim TJ, Deviren V, Ames CP: Biomechanical analysis of Goel technique for C1-2 fusion. Laboratory investigation. J Neurosurg Spine 14:639-646, 2011

24. Pathria M, Sartoris DJ, Resnick D: Osteoarthritis of the facet joints: accuracy of oblique radiographic assessment. Radiology 164:227-230, 1987

25. Raynor RB, Moskovich R, Zidel P, Pugh J: Alterations in primary and coupled neck motions after facetectomy. Neurosurgery 21:681-687, 1987

26. Raynor RB, Pugh J, Shapiro I: Cervical facetectomy and its effect on spine strength. J Neurosurg 63:278-282, 1985

27. Sohn HM, You JW, Lee JY: The relationship between disc degeneration and morphologic changes in the intervertebral foramen of the cervical spine: a cadaveric MRI and CT study. J Korean Med Sci 19:101-106, 2004

28. Takemitsu M, Cheung KM, Wong YW, Cheung WY, Luk KD: C5 nerve root palsy after cervical laminoplasty and posterior fusion with instrumentation. J Spinal Disord Tech 21:267272,2008

29. Tanaka N, Nakanishi K, Fujiwara Y, Kamei N, Ochi M: Postoperative segmental C5 palsy after cervical laminoplasty may occur without intraoperative nerve injury: a prospective study with transcranial electric motor-evoked potentials. Spine (Phila Pa 1976) 31:3013-3017, 2006

30. Taylor JR, Twomey LT: Age changes in lumbar zygapophyseal joints. Observations on structure and function. Spine (Phila Pa 1976) 11:739-745, 1986

31. Traynelis VC: Total subaxial reconstruction. Clinical article. J Neurosurg Spine 13:424-434, 2010

32. Yang KH, King AI: Mechanism of facet load transmission as a hypothesis for low-back pain. Spine (Phila Pa 1976) 9:557565,1984

33. Yoo JU, Zou D, Edwards WT, Bayley J, Yuan HA: Effect of cervical spine motion on the neuroforaminal dimensions of human cervical spine. Spine (Phila Pa 1976) 17:1131-1136, 1992

34. Zdeblick TA, Zou D, Warden KE, McCabe R, Kunz D, Vanderby R: Cervical stability after foraminotomy. A biomechanical in vitro analysis. J Bone Joint Surg Am 74:22-27, 1992

Manuscript submitted January 3, 2013.

Accepted November 12, 2013.

Portions of this work were presented as an abstract at the 28th Annual Meeting of the AANS/CNS Section on Disorders of the Spine and Peripheral Nerves, March 7-10, 2012, Orlando, Florida.

Please include this information when citing this paper: published online December 13, 2013; DOI: 10.3171/2013.11.SPINE131.

Address correspondence to: Vincent C. Traynelis, M.D., Department of Neurosurgery, Rush University Medical Center, 1725 W. Harrison St., Ste. 855, Chicago, IL 60612. email: Vincent_Traynelis @ rush.edu. 